\title{
Molecular phylogenetic confirmation of Gnathostoma spinigerum Owen, 1836 (Nematoda: Gnathostomatidae) in Laos and Thailand
}

\author{
Jurairat Jongthawin ${ }^{1,2}$, Pewpan M. Intapan ${ }^{1,2}$, Oranuch Sanpool ${ }^{1,2,3}$, Penchom Janwan ${ }^{4}$, Lakkhana Sadaow Sa, $^{1,2}$ \\ Tongjit Thanchomnang ${ }^{3}$, Sakhone Laymanivong ${ }^{2,5}$ and Wanchai Maleewong ${ }^{1,2}$ \\ ${ }^{1}$ Research and Diagnostic Center for Emerging Infectious Diseases, Khon Kaen University, Khon Kaen, Thailand; \\ ${ }^{2}$ Department of Parasitology, Faculty of Medicine, Khon Kaen University, Khon Kaen, Thailand; \\ ${ }^{3}$ Faculty of Medicine, Mahasarakham University, Mahasarakham, Thailand; \\ ${ }^{4}$ Department of Medical Technology, School of Allied Health Sciences and Public Health, Walailak University, Nakhon Si \\ Thammarat, Thailand; \\ ${ }^{5}$ Laboratory Unit, Centre of Malariology, Parasitology and Entomology, Ministry of Health, Lao People’s Democratic Republic
}

\begin{abstract}
We report the molecular-phylogenetic identification of larvae of the nematode genus Gnathostoma Owen, 1836 collected from a snake, Ptyas koros Schlegel, in Laos and adult worms from the stomach of a dog in Thailand. DNA was extracted and amplified targeting the partial coxl gene and the ITS-2 region of ribosomal DNA. Phylogenetic analyses indicated that all five advanced thirdstage larvae and seven adult worms were Gnathostoma spinigerum Owen, 1836. This is also the first molecular evidence of infection with G. spinigerum in a snake from Laos.
\end{abstract}

Keywords: ITS-2 rDNA, genotyping, parasitic nematode, fish-borne helminthoses, molecular taxonomy, South-East Asia

Gnathostomiasis is a zoonotic disease caused by nematode parasites of the genus Gnathostoma Owen, 1836. Dogs and cats are the main natural definitive hosts and humans are accidentally infected by acquiring larvae via ingestion of insufficiently cooked meat of the second intermediate hosts or paratenic hosts such as fish, frogs and snakes, and also by skin penetration of the larvae from such meat (Waikagul and Diaz-Camacho 2007). Human cases have been reported predominantly in Japan and Southeast Asian countries including Thailand. Gnathostoma spinigerum Owen, 1836 has been identified as causative agent of these infections (Waikagul and Diaz-Camacho 2007).

Gnathostoma nipponicum Yamaguti, 1941, Gnathostoma doloresi Tubangui, 1925 and Gnathostoma hispidum Fedchenko, 1972 have also been reported as human parasite in Japan (Waikagul and Diaz-Camacho 2007). In Mexico, Gnathostoma binucleatum Almeyda-Artigas, 1991 represents the main causative agent of gnathostomosis (Almeyda-Artigas et al. 2000). In non-endemic countries, health issues may arise from imported cases, i.e. an infection contracted while visiting an endemic country (Herman and Chiodini 2009).
Identification of worms from humans and natural hosts is traditionally done using morphological criteria (Akahane et al. 1986) but molecular approaches are useful method for identification of species of Gnathostoma (see Almeyda-Artigas et al. 2000, Ando et al. 2006, Jongthawin et al. 2015). However, molecular evidence of the occurrence of species of Gnathostoma in wildlife in Asian countries including Laos and Thailand is still lacking.

We analysed the partial sequences of mitochondrial cytochrome c-oxidase subunit I ( coxl) gene and full-length ITS-2 region of ribosomal DNA of a Gnathostoma species isolated from a snake (Ptyas korros Schlegel; Colubridae) collected in Laos. Nucleotide sequences of coxl and ITS2 of $G$. spinigerum adults recovered from the stomach of a domestic dog (Canis lupus familiaris Linnaeus) in Thailand and from DNA databases were used for phylogenetic analysis to explore the relationships.

One sample of P. korros (commonly known as the Chinese rat snake or Indo-Chinese rat snake) was bought at a local food market in Khammouane Province, Laos. The snake harboured 90 advanced third-stage larvae $\left(\mathrm{AdvL}_{3}\right)$ of Gnathostoma, five of which were microscopically iden-

Address for correspondence: W. Maleewong, Department of Parasitology, Faculty of Medicine, Khon Kaen University, Khon Kaen 40002, Thailand. Phone: +66-43-348387; Fax: +66-43-202475; E-mail: wanch_ma@kku.ac.th 


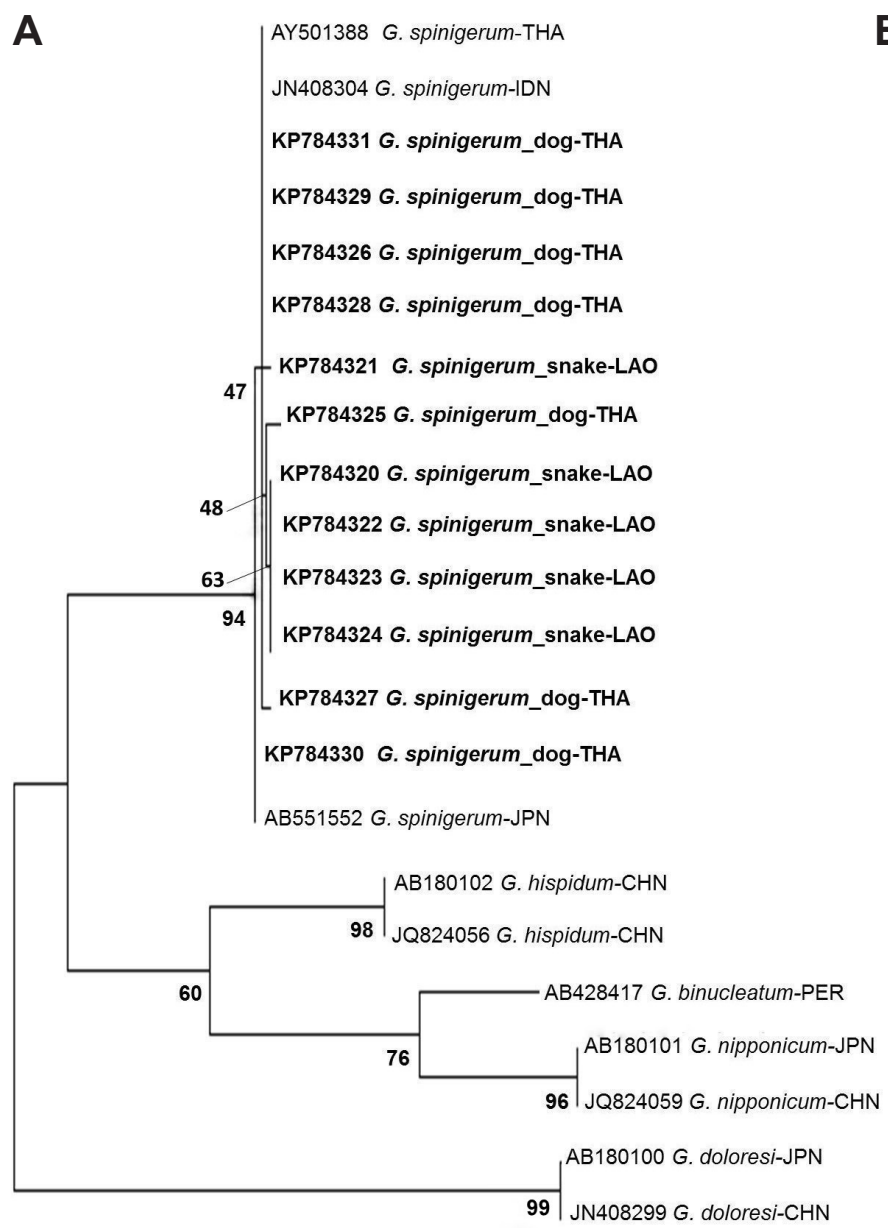

B

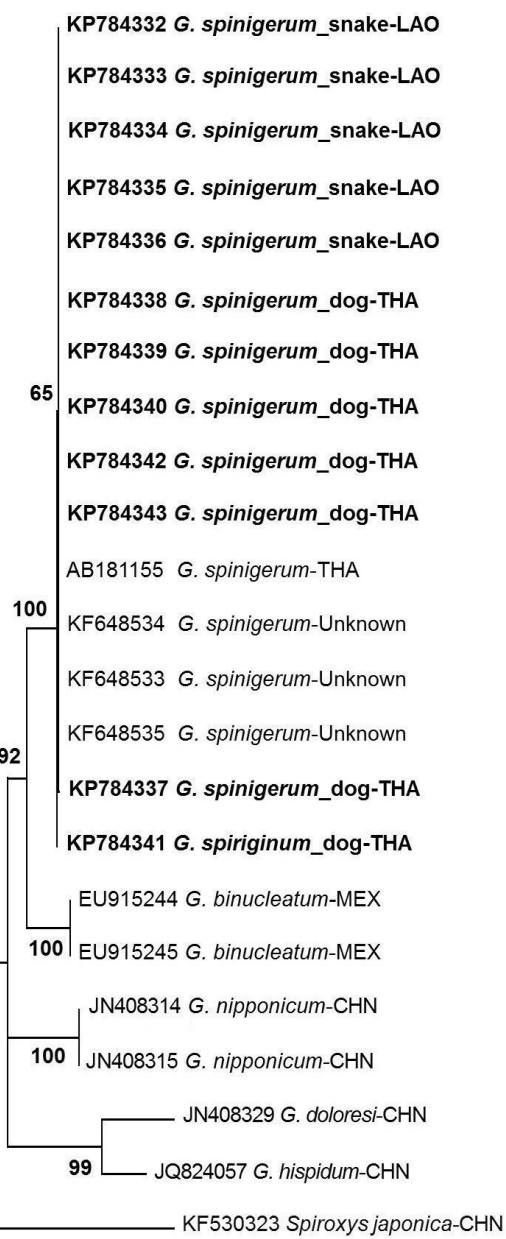

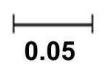

0.2

Fig. 1. Phylogenetic relationship among species of Gnathostoma Owen, 1836. Trees were reconstructed using the maximum likelihood method based on partial coxl (A) and ITS-2 sequences (B). Sequences of species of Gnathostoma obtained from GenBank are indicated with the accession number and the country code (ISO 3166-1 alpha-3 code). Sequences obtained in the present study are highlighted in bold. Bootstrap scores, expressed as percentages of 1000 replications, are given at each node. Scale bars indicate substitutions per nucleotide position.

tified as G. spinigerum and selected for molecular identification. Seven adult worms were obtained from the stomach of a domestic dog at Animal Hospital, Faculty of Veterinary Medicine, Khon Kaen University; the parasites were microscopically identified as G. spinigerum based on characteristics presented by Daengsvang (1980). All parasites were preserved in $70 \%$ ethanol and kept in the freezer $-80^{\circ} \mathrm{C}$ before DNA extraction.

Genomic DNA was extracted from individual $\mathrm{AdvL}_{3}$ and adult worms using a DNA extraction kit (NucleoSpin $^{\circledR}$ Tissue, Macherey-Nagel, Germany). A partial coxl gene and partial 5.8S, entire ITS2 and partial 28S regions were amplified using the primers Gn_COI (forward: 5'-GCCTGCTTTTGGAATTGTTAG-3', reverse: 5'-ACGAAAACCATACAAAGTAGCCAA-3') and GS ITS2 (forward: 5'-TGTGTCGATGAAGAACGCAG-3', reverse: 5'-TTCTATGCTTAAATTCAGGGG-3'), respectively, which were genus-specific for Gnathostoma.

Each polymerase chain reaction (PCR) was performed according to the previous method (Jongthawin et al. 2015).
Amplicons were subjected to agarose gel electrophoresis (1.5\% gel); 250 bp of cox 1 and 650 bp of partial $5.8 \mathrm{~S}$, entire ITS2 and partial 28S regions fragments were cut and purified. Samples for sequencing were prepared using BigDye $^{\circledR}$ Terminator v3.1 cycle sequencing kit (Foster City, CA, USA) and sequenced using a 3730xI DNA Analyzer (ABI). All DNA fragments were sequenced in both directions, employing the same primers as used in each PCR.

The partial sequence of $\operatorname{cox} 1$ gene and the complete sequence of the ITS-2 region from each $G$. spinigerum isolates were analysed using the BLAST-N search tool (National Center for Biotechnology Information, Bethesda, MD, USA). The new G. spinigerum sequences of samples from both countries were aligned with the sequences from the GenBank database (alignment length was 205 bp long for cox 1 and $472 \mathrm{bp}$ for the full length of ITS-2) using the Bioedit sequence alignment editor (Hall 1999).

Phylogenetic relationships were inferred using the maximum likelihood method implemented in MEGA v6 (Tamura et al. 2013). The best substitution model for cox 1 was 
Table 1. Tamura-Nei model (Tamura and Nei 1993) genetic distance matrix values based on partial coxl gene sequences among 12 isolates of Gnathostoma spinigerum Owen, 1836 and related sequences of G. spinigerum from the Genbank database.

\begin{tabular}{llcccccccccccccc}
\hline & 1 & 2 & 3 & 4 & 5 & 6 & 7 & 8 & 9 & 10 & 11 & 12 & 13 & 14 & 15 \\
\hline 1 & KP784320_LAO & & & & & & & & & & & & & \\
2 & KP784321_LAO & 0.010 & & & & & & & & & & & & \\
3 & KP784322_LAO & 0.000 & 0.010 & & & & & & & & & & \\
4 & KP784323_LAO & 0.000 & 0.010 & 0.000 & & & & & & & & & & \\
5 & KP784324_LAO & 0.000 & 0.010 & 0.000 & 0.000 & & & & & & & & & & \\
6 & KP784325_THA & 0.010 & 0.015 & 0.010 & 0.010 & 0.010 & & & & & & & & \\
7 & KP784326_THA & 0.005 & 0.005 & 0.005 & 0.005 & 0.005 & 0.010 & & & & & & & & \\
8 & KP784327_THA & 0.010 & 0.010 & 0.010 & 0.010 & 0.010 & 0.015 & 0.005 & & & & & & & \\
9 & KP784328_THA & 0.005 & 0.005 & 0.005 & 0.005 & 0.005 & 0.010 & 0.000 & 0.005 & & & & & & \\
10 & KP784329_THA & 0.005 & 0.005 & 0.005 & 0.005 & 0.005 & 0.010 & 0.000 & 0.005 & 0.000 & & & & \\
11 & KP784330_THA & 0.010 & 0.010 & 0.010 & 0.010 & 0.010 & 0.015 & 0.005 & 0.010 & 0.005 & 0.005 & & & & \\
12 & KP784331_THA & 0.005 & 0.005 & 0.005 & 0.005 & 0.005 & 0.010 & 0.000 & 0.005 & 0.000 & 0.000 & 0.005 & & & \\
13 & AB551552 G. spinigerum_JPN & 0.010 & 0.010 & 0.010 & 0.010 & 0.010 & 0.015 & 0.005 & 0.010 & 0.005 & 0.005 & 0.000 & 0.005 & \\
14 & AY501388 G. spinigerum_THA & 0.005 & 0.005 & 0.005 & 0.005 & 0.005 & 0.010 & 0.000 & 0.005 & 0.000 & 0.000 & 0.005 & 0.000 & 0.005 & \\
15 & JN408304 G. spinigerum_IDN & 0.005 & 0.005 & 0.005 & 0.005 & 0.005 & 0.010 & 0.000 & 0.005 & 0.000 & 0.000 & 0.005 & 0.000 & 0.005 & 0.000 \\
\hline
\end{tabular}

Table 2. Tamura-Nei model (Tamura and Nei 1993) genetic distance matrix values based on ITS-2 sequences among 12 isolates of Gnathostoma spinigerum Owen, 1836 and related sequences of G. spinigerum from the Genbank database.

\begin{tabular}{|c|c|c|c|c|c|c|c|c|c|c|c|c|c|c|c|}
\hline & & 1 & 2 & 3 & 4 & 5 & 6 & 7 & 8 & 9 & 10 & 11 & 12 & 13 & 14 \\
\hline 1 & KP784332_LAO & & & & & & & & & & & & & & \\
\hline 2 & KP784333_LAO & 0.000 & & & & & & & & & & & & & \\
\hline 3 & KP784334_LAO & 0.000 & 0.000 & & & & & & & & & & & & \\
\hline 4 & KP784335_LAO & 0.000 & 0.000 & 0.000 & & & & & & & & & & & \\
\hline 5 & KP784336_LAO & 0.000 & 0.000 & 0.000 & 0.000 & & & & & & & & & & \\
\hline 6 & KP784337_THA & 0.002 & 0.002 & 0.002 & 0.002 & 0.002 & & & & & & & & & \\
\hline 7 & KP784338_THA & 0.000 & 0.000 & 0.000 & 0.000 & 0.000 & 0.002 & & & & & & & & \\
\hline 8 & KP784339_ТHA & 0.000 & 0.000 & 0.000 & 0.000 & 0.000 & 0.002 & 0.000 & & & & & & & \\
\hline 9 & KP784340_THA & 0.000 & 0.000 & 0.000 & 0.000 & 0.000 & 0.002 & 0.000 & 0.000 & & & & & & \\
\hline 10 & KP784341_THA & 0.002 & 0.002 & 0.002 & 0.002 & 0.002 & 0.003 & 0.002 & 0.002 & 0.002 & & & & & \\
\hline 11 & KP784342_ТHA & 0.000 & 0.000 & 0.000 & 0.000 & 0.000 & 0.002 & 0.000 & 0.000 & 0.000 & 0.002 & & & & \\
\hline 12 & KP784343_THA & 0.000 & 0.000 & 0.000 & 0.000 & 0.000 & 0.002 & 0.000 & 0.000 & 0.000 & 0.002 & 0.000 & & & \\
\hline 13 & AB181155 G. spinigerum_THA & 0.000 & 0.000 & 0.000 & 0.000 & 0.000 & 0.002 & 0.000 & 0.000 & 0.000 & 0.002 & 0.000 & 0.000 & & \\
\hline 14 & KF648533 G. spinigerum_Unknown & 0.000 & 0.000 & 0.000 & 0.000 & 0.000 & 0.002 & 0.000 & 0.000 & 0.000 & 0.002 & 0.000 & 0.000 & 0.000 & \\
\hline
\end{tabular}

Hasegawa-Kishino-Yano (HKY) + G + I, and for the ITS2 region was Kimura-2-parameter $(\mathrm{K} 2 \mathrm{P})+\mathrm{I}$. The selected dataset and support for clusters in each tree was calculated using 1000 bootstrap replications. Sequences of other species of Gnathostoma from the database were used for the alignment. Genetic distance values among isolates from Thailand and Laos were calculated using Tamura-Nei model (Tamura and Nei 1993) (Tables 1, 2, Fig. 1).

For cox 1 gene sequences, a $250 \mathrm{bp}$ PCR product was amplified from all specimens. After trimming the primer sequences, five $(2.4 \%)$ variable sites in the 205 bp alignment were analysed. Transitions ( $\mathrm{T} \leftrightarrow \mathrm{C}, \mathrm{n}=1 ; \mathrm{A} \leftrightarrow \mathrm{G}$, $\mathrm{n}=4$ ) were more frequently observed than transversions ( $\mathrm{T} \leftrightarrow \mathrm{G}, \mathrm{n}=1 ; \mathrm{T} \leftrightarrow \mathrm{A}, \mathrm{n}=1$ ) (the nucleotide position 94 in the analysed sequences has both transition and transversion). In the phylogenetic tree inferred from partial coxl sequences (Fig. 1A), all isolates from Thailand and Laos formed the same clade with known sequences of isolates of G. spinigerum (from Japan, Thailand and Indonesia) in the GenBank database.

For a partial 5.8S, entire ITS-2 and partial 28S regions, a $650 \mathrm{bp}$ PCR product was amplified from all worms. The full-length ITS-2 region (472 bp) of each sample was aligned and two $(0.4 \%)$ variable sites were detected (tran- sitions: $T \leftrightarrow C, n=1 ; A \leftrightarrow G, n=1)$. In the phylogenetic tree inferred from full-length ITS-2 region (Fig. 1B), all isolates from Thailand and Laos formed the same clade with known sequences of $G$. spinigerum (from undetermined Asian countries in the GenBank database and Thailand). The relationships among 12 isolates of $G$. spinigerum and related sequences were revealed by genetic distance values; 0.005-0.015 for partial coxl (Table 1) and 0.002-0.003 for ITS-2 (Table 2). All partial coxl and partial 5.8S, entire ITS-2 and partial 28S regions of $G$. spinigerum have been deposited in the GenBank database under accession No. KP784320-KP784331 and KP784332-KP784343, respectively (Fig. 1).

Some groups of people living in Thailand and Laos maintain their traditional life-style of eating local dishes prepared from raw or semi-cooked fish contaminated with infective $\mathrm{AdvL}_{3}$ of species of Gnathostoma (see Nawa and Nakamura-Uchiyama 2004). In Laos, $\mathrm{AdvL}_{3}$ of Gnathostoma spp. have been found in four species of edible fish and one species of frog (Vonghachack et al. 2010). We here found new molecular evidence of $\mathrm{AdvL}_{3}$ of $G$. spinigerum in a snake, P. korros, in Khammouane province, Laos, and confirmed using molecular markers the occurrence of adults of G. spinigerum in Thailand. 
In Thailand, the country with high prevalence of gnathostomiasis, fish, frogs, reptiles, birds and mammals have been reported to harbour $\mathrm{AdvL}_{3}$ of $G$. spinigerum, wherease dogs were found to be the definitive host of this nematode (Maleewong et al. 1992). A new type of Gnathostoma larvae reported by Akahane et al. (1995) and Setasuban et al. (1991) may belong to either Gnathostoma vietnamicum Le-Van-Hoa, 1965, Gnathostoma malaysiae Miyazaki and Dunn, 1965 or may constitute a new species of the genus Gnathostoma. Using partial cox 1 gene and ITS-2 sequences as molecular markers, all samples were identified as G. spinigerum. Some intraspecific variation was observed in coxl gene sequences from two geographic regions (genetic distance; $0.005-0.015)$, little or no intraspecific var- iation was detected in the ITS-2 region (genetic distance; $0.002-0.003)$.

Acknowledgements. This study was supported by a TRF Senior Research Scholar Grant, Thailand Research Fund grant number RTA5880001; Higher Education Research Promotion and National Research University Project of Thailand, Office of the Higher Education Commission, Thailand, through the Health Cluster (SHeP-GMS); Post-Doctoral Training Program of Graduate School and Khon Kaen University (grant No. 58105), Khon Kaen University; and Faculty of Medicine, Khon Kaen University (TR57201). We would like to thank Yukifumi Nawa (Khon Kaen University Publication Clinic) for valuable suggestions for improving the quality of this manuscript.

\section{REFERENCES}

Akahane H., Sano M., Mako T. 1986: Morphological difference in cross sections of the advanced third stage larvae of Gnathostoma spinigerum, G. hispidum and G. doloresi. Jpn. J. Parasitol. 35: 465-467.

Akahane H., Setasuban P., Nuamtanong S., Horiuchi S., Koga M., Kojima S. 1995: A new type of advanced third-stage larvae of the genus Gnathostoma in freshwater eels, Fluta alba, from Nakhon Nayok, central Thailand. Southeast Asian J. Trop. Med. Publ. Hlth. 26: 743-747.

Almeyda-Artigas R.J., Bargues M.D., Mas-Coma S. 2000: ITS-2 rDNA sequencing of Gnathostoma species (Nematoda) and elucidation of the species causing human gnathostomiasis in the Americas. J. Parasitol. 86: 537-544.

Ando K., Tsunemori M., Akahane H., Tesana S., Hasegawa H., Chinzei Y. 2006: Comparative study on DNA sequences of ribosomal DNA and cytochrome $c$ oxidase subunit 1 of mitochondrial DNA among five species of gnathostomes. J. Helminthol. 80: 7-13.

Daengsvang S. (Ed.) 1980: A Monograph on the Genus Gnathostoma and Gnathostomiasis in Thailand. Southeast Asian Medical Information Center (SEAMIC), Tokyo, 118 pp.

HALl T.A. 1999: BioEdit: a user-friendly biological sequence alignment editor and analysis program for Windows 95/98/NT. Nucl. Acids Symp. Ser. 41: 95-98.

Herman J.S., Chiodini P.L. 2009: Gnathostomiasis, another emerging imported disease. Clin. Microbiol. Rev. 22: 484-492.

Jongthawin J., Intapan P.M., Sanpool O., SAdaOw L., JanWan P., Thanchomnang T., Sangchan A., Visaetsilpanonta S., Keawkong W., Maleewong W. 2015: Three human gnathostomiasis cases in Thailand with molecular iden- tification of causative parasite species. Am. J. Trop. Med. Hyg. 93: 615-618.

Maleewong W., Pariyanonda S., Sitthithaworn P., DaenSeegaew W., Pipitgool V., Tesana S., Wongkham C., InTAPAN P.M., Morakote N. 1992: Seasonal variation in the prevalence and intensity of canine Gnathostoma spinigerum infection in northeastern Thailand. J. Helminthol. 66: 72-74.

Nawa Y., Nakamura-Uchiyama F. 2004: An overview of gnathostomiasis in the world. Southeast Asian J. Trop. Med. Publ. Hlth. 35 (Suppl. 1): 87-91.

Setasuban P., Nuamtanong S., Rojanakittikoon V., Yaemput S., Dekumyoy P., Akahane H., Kojima S. 1991: Gnathostomiasis in Thailand: a survey on intermediate hosts of Gnathostoma spp. with special reference to a new type of larvae found in Fluta alba. Southeast Asian J. Trop. Med. Publ. Hlth. 22 (Suppl.): 220-224.

Tamura K., Nei M. 1993: Estimation of the number of nucleotide substitutions in the control region of mitochondrial DNA in humans and chimpanzees. Mol. Biol. Evol. 10: 512-526.

Tamura K., Stecher G., Peterson D., Filipski A., Kumar S. 2013: MEGA6: Molecular Evolutionary Genetics Analysis version 6.0. Mol. Biol. Evol. 30: 2725-2729.

Vonghachack Y., Dekumyoy P., Yoonuan T., Sa-nguankiat S., Nuamtanong S., Thaenkham U., Phommasack B., Kobayashi J., Waikagul J. 2010: Sero-epidemiological survey of gnathostomiasis in Lao PDR. Parasitol. Int. 59: 599-605.

Waikagul J., Diaz-Camacho S.P. 2007: Gnathostomiasis. In: K.D. Murrell and B. Fried (Eds.), Food-Borne Parasitic Zoonoses. Springer, New York, pp. 235-226. 